\title{
Evaluation of Mechanical Performance and Flame Retardant Characteristics of Biomass-based EVA Composites using Intumescent Flame Retardant Technology ${ }^{1}$
}

\author{
Ji-Won Park ${ }^{2,3} \cdot$ Hoon $\mathrm{Kim}^{2} \cdot$ Jung-Hun Lee ${ }^{2} \cdot$ Seong-Wook Jang ${ }^{2,3} \cdot$ Hyun-Joong Kim (D) ${ }^{2,3, \dagger}$
}

\begin{abstract}
Intumescent system is a highly effective flame retardant technology that takes advantage of the mechanism of foaming and carbonization. In order to materialize Intumescent system, it is necessary to use reinforcement material to improve the strength of the material. In this study, we used kenaf as a natural fiber to manufacture intumescent/EVA (ethylene vinyl acetate) composites to improve mechanical and flame retardant performance. Finally two materials with different particle shape are applied to one system. Therefore, the influence factors of the particles with different shapes on the composite material were analyzed based on the tensile test. For this purpose, we have used the tensile strength analysis model and confirmed that it can only act as a partial strength reinforcement due to weak binding force between the matrix and particles. In the combustion characteristics analysis using cone calorimeter and UL 94, the combustion characteristics were enhanced as the content of Intuemscent was increased. As the content of kenaf increased, combustion characteristics were strengthened and carbonization characteristics were weakened. Through the application of kenaf, it can be confirmed that elastic modulus improvement and combustion characteristics can be strengthened, which confirmed the possibility of development of environmentally friendly flame retardant materials.
\end{abstract}

Keywords: eco-friendly composites, flame retardant, intumescent system, kenaf fiber, strength prediction model

\section{INTRODUCTION}

As the materials of the buildings are diversified, the characteristics that the materials must have are also increasing. Among them, flame-retardant technology is an essential element of building materials (Harper, 2004). There are various ways to apply the flame retardant properties, but among them, the surface treatment method has a great advantage that it can be applied to a completed architecture. There are coating and lamination methods for the flame retardant treatment through surface treatment ( $\mathrm{Gu}, 2007)$. The lamination method is advantageous in that various materials and shapes can be taken by attaching materials such as films.

Early flame retarding techniques have been approached

\footnotetext{
${ }^{1}$ Date Received December 13, 2017, Date Accepted March 13, 2018

${ }^{2} \mathrm{Lab}$ of Adhesion and Bio-Composite, Program in Environmental Materials Science, Department of Forest Science, Seoul National University, Seoul 08826, Republic of Korea

${ }^{3}$ Research Institute of Agriculture and Life Sciences, Seoul National University, Seoul 08826, Republic of Korea

$\dagger$ Corresponding author: Hyun-Joong Kim(e-mail: hjokim@snu.ac.kr, ORCID: 0000-0002-3897-7939)
} 
in a way that utilizes halogen substituent ( $\mathrm{Lu}, 2002)$. The halogen substituent can effectively prevent combustion from proceeding while acting as a stabilizer of the radical in the combustion process. However, when the stabilizer effect is exhausted and starts the combustion, the combustible material by the halogen material has a fatal influence on the human body. These characteristics were the main cause of death due to asphyxiation, not fire injury. In order to overcome these disadvantages, flame retardant materials using nonhalogen type materials have been introduced, and flame retardant materials using a phosphor based material have been developed in various ways. However, in order to secure the flame retardancy through the phosphorus material, it is pointed out that it is a limitation point of the application of the material because it needs to use more material than the conventional flame retardant materials (Levchik, 2006).

The Intumescent system is a flame retardant system that utilizes a combination of polymer foam / carbonation layer formation that swells as a result of heat exposure, thus increasing in volume and decreasing in density (Li 2006). A carbonized layer and an air layer are simultaneously generated to form a strong isolation structure. Although it is not a technique to intensify the flame retardancy of the material itself, it is considered to be an effective technique for reducing the maximum calorific value and delaying the flashover arrival because it delays the burning time from the surface to the deep portion. Since the Intumescent system is not utilized in an independent structure, it is useful to apply it in film or sheet that composed of a polymer composites ( $\mathrm{Wu}, 2009$ ).

The intumescent agent is a monomolecular particle, which causes the strength of the material to drop in the composite process. Particularly, when the strength of the matrix is weak, this characteristic causes a great problem such as reduction of stability and moldability of the material. Therefore, there is a need for a strength reinforcement technique that can overcome these disadvantages. Fiber composites are the most representative technique for improving strength. In particular, recently, a variety of composite materials that utilize biomass-based fibers to complement the environment has been researched (Tang, 2003).

In this study, we analyzed strength changes of flame retardant composite materials using intumescent particles. And it studied the effect of improving the strength utilizing biomass-based fiber system in combination. Finally, the combustion characteristics of the flame retardant composite were confirmed by UL94 test and Cone Calorimeter.

\section{MATERIALS and METHODS}

\subsection{Materials}

For the sheet-shaped composite material, a polymer having excellent flexibility, melting property and adhesiveness was used as a matrix. Ethylene Vinyl Acetate (EVA) is a copolymer of ethylene and vinyl acetate. EVA shows various performance depending on the content of vinyl acetate. EVA is excellent for softness and flexibility and is suitable as a matrix. EVA was VS420 LOTTE chemical, Republic of Korea. The content of VA is $21.5 \%$ and a melt index of $2.0 \mathrm{~g} / 10$ min is suitable for forming foam.

Foaming agent, carbide foamer and catalyst are required to implement Intumescent system. Each material has a structure in which the foaming and the carbonization layer formation are continuously generated to maximize the flame retardancy depending on the carbonized layer and the foamed layer on the near surface. Ammonium phosphate monobasic (APP, SigmaAldrich, USA) was used as a catalyst, and melamine (MEL, Sigma-Aldrich, USA) was used as a carbide foamer and pentaerythritol (PER, Sigma-Aldrich, USA) was used as a foaming agent. 
Evaluation of Mechanical Performance and Flame Retardant Characteristics of Biomass-based EVA Composites using Intumescent Flame Retardant Technology

Table 1. Sample preparation ratio (Compare group 1: Sample 1 5, group 2: 5 8)

\begin{tabular}{cccc}
\hline Sample List & EVA & APP:PER:MEL [3:1:1] $(\mathrm{phr})$ & Kenaf Fiber \\
\hline \hline 1 & 100 & 0 & 0 \\
2 & 100 & 10 & 0 \\
3 & 100 & 20 & 0 \\
4 & 100 & 30 & 0 \\
5 & 100 & 40 & 0 \\
6 & 100 & 40 & 5 \\
7 & 100 & 40 & 10 \\
8 & 100 & 40 & 20 \\
\hline
\end{tabular}

Fiber reinforced plastic is a typical composite material that enhances the mechanical strength of polymers. To improve the strength of intumescent/EVA composites, natural fibers were used. The fibers used in this study are kenaf fibers. Kenaf is a plant in the Malvaceae family also called Deccan hemp and Java jute. Kenaf fibers, which were imported from Bangladesh. Kenaf fibers were finely ground to a size which can pass through a filter of 40 mesh size by a disintegrator (CTM 200 in Kukje Scientific Instrument, Korea).

The composite was produced through a twin screw extruder (Bautek, 19 pi, Pocheon, Korea). The barrel temperature (in Celsius) zone of the extruder was as follows: 70/80/90/100/100/100/100/90. The screw speed was maintained at $150 \mathrm{rpm}$. Composite with intumescent agent and EVA were first prepared. Among them, composites using kenaf were prepared by using intumescent $40 \mathrm{phr}$ (parts per hundred resin) test specimen, which has the most excellent flame retardancy and worst mechanical performance. The composition ratio of all materials is listed in Table 1 .

\subsection{Tensile Strength Test}

Tensile and flexural specimens were measured using the universal testing machine (Zwick Co, Germany) by ASTM D 638 - 10 and ASTM D $790-10$. When measured, A cross speed of machine was $5 \mathrm{~mm} / \mathrm{min}$ and the mechanical properties were analyzed at room temperature. Five specimens were measured to calculate the margin of error.

\subsection{Combustion Test}

Cone Calorimeter (ISO 5660-1\&2) and UL94 (the Standard for Safety of Flammability of Plastic Materials for Parts in Devices and Appliances testing) experiments were conducted to analyze the flame retardant properties of the prepared test samples. Each sample was prepared in the form of $100 \times 100 \times 3\left(\mathrm{~mm}^{3}\right)$, $13 \times 125 \times 3\left(\mathrm{~mm}^{3}\right)$. Samples were produced in the form of press squeeze. Therefore, it is estimated that there is no influence factor by directionality due to injection and extrusion. The UL 94 test can be evaluated in V0, $\mathrm{V} 1, \mathrm{~V} 2$ grades and V0 grades are required to be used as nonflammable materials. The criteria for distinguishing each grade are described in the following Table 2.

The cone calorimeter test is a combustion characteristic test for the building interior materials, interior materials for railway vehicles, indoor decorations, etc. specified by the Building Code and Fire Prevention Act. The cone calorimeter test is a system for quantitatively measuring fire parameters such as ignition time, heat release rate, mass reduction rate, and total smoke emission during the material exposure to fire conditions. 
Table 2. Grading criteria of UL94

\begin{tabular}{|c|c|c|c|}
\hline & $\mathrm{V}-0$ & V-1 & $\mathrm{V}-2$ \\
\hline After flame time for each individual specimen $\mathrm{t} 1$ or $\mathrm{t} 2$ & $\leq 10 \mathrm{~s}$ & $\leq 30 \mathrm{~s}$ & $\leq 30 \mathrm{~s}$ \\
\hline Total after flame time for any condition set ( $\mathrm{t} 1$ plus $\mathrm{t} 2$ for the 5 specimens) & $\leq 50 \mathrm{~s}$ & $\leq 250 \mathrm{~s}$ & $\leq 250 \mathrm{~s}$ \\
\hline $\begin{array}{l}\text { After flame or after glow time for each individual specimen after the second } \\
\text { flame application }(\mathrm{t} 2+\mathrm{t} 3)\end{array}$ & $\leq 30 \mathrm{~s}$ & $\leq 60 \mathrm{~s}$ & $\leq 60 \mathrm{~s}$ \\
\hline After flame or after glow of any specimen up to the holding clamp & No & No & No \\
\hline Cotton indicator ignited by flaming particles or drops & No & No & Yes \\
\hline
\end{tabular}

\section{RESULTS and DISCUSSION}

\subsection{Tensile Strength Analysis in Hybrid Filler System}

In order to predict the performance of intumescent agent and kenaf composite material, we compared the performance prediction model and the experimental results. In order to evaluate the performance of composite materials using only intumescent agent, we tried to select a model that can analyze the influence factors on particles. First, Einstein equation known as the simplest model for analyzing Elastic Modulus, was used to analyze performance differences.

$$
E=E_{m}\left(1+2.5 V_{f}\right)
$$

The above model predict the small strain Young's modulus of particle-filled solids. $\mathrm{E}_{\mathrm{m}}$ is the Young's modulus of the matrix material and $\mathrm{V}_{\mathrm{f}}$ is the volume fraction filler. We used the modified model as Guth $\&$ Simha and the model Govindjee \& Simo based on rigid particles.

$$
\begin{gathered}
E=E_{m}\left(1+2.5 V_{f}+14.1 V_{f}^{2}\right) \\
E=E_{m} \frac{1-V_{f} / 2}{1-V_{f}} \quad \ldots \ldots \ldots . . .
\end{gathered}
$$

The above three models predict the change of modulus according to the volume fraction of particles used together. Particle-phase particles have no aniso- tropic properties with respect to modulus analysis. The elastic modulus model based on the volume can be utilized only when the particles having a higher modulus than the matrix are utilized. In all three basic models, the elastic modulus increases as the filler content increases. As the content of the intumescent agent increases, the elastic modulus tends to increase. The pure EVA was estimated to be $12.21 \mathrm{MPa}$, and when the intumescent agent content was $40 \mathrm{phr}$, it was increased by $60 \%$ to $19.59 \mathrm{MPa}$. The average density of the intumescent agent was $1.674 \mathrm{~g} / \mathrm{cm}^{3}$ and the average density of EVA was $0.94 \mathrm{~g} / \mathrm{cm}^{3}$. When the content of intumescent agent increased to 5, 10, 20, 30 and $40 \mathrm{phr}$, the volume fraction of intumescent agent was 2.7, 5.3, 10.0, 14.4 and 18.3\% (Fig. 1).

The intumescent agent is a inorganic-based material with a high modulus of elasticity. As the content of

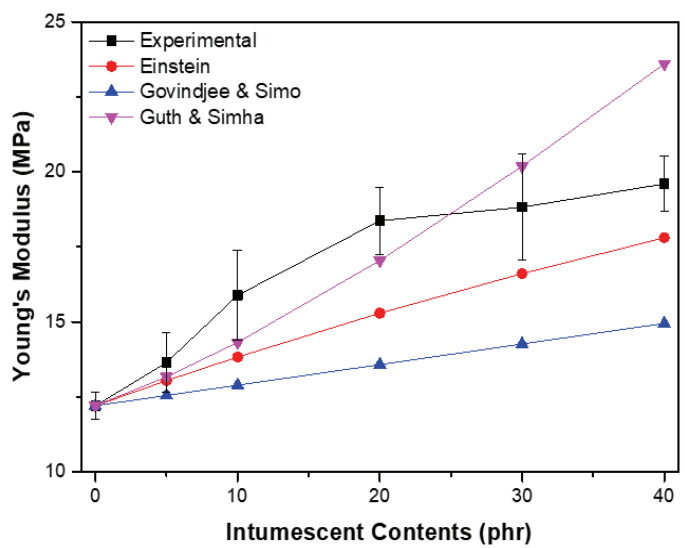

Fig. 1. Elastic modulus of intumescent/EVA composites. 

using Intumescent Flame Retardant Technology

these materials increases, the modulus of elasticity of the composite generally increases. The feature of the three models is that they can be used when the influence between the binder and the filler is small and the fraction of the filler is small. For the Govindjee \& Simo model which varies with the volume fraction, the variation range is the smallest. It can be used as the most suitable model when there is almost no coupling force between the filler and the matrix. On the other hand, the Einstein model and the Guth \& Simha model are based on the increase in the modulus of elasticity with the influence of the filler, and it can be confirmed that the two models are very similar to the experimental results. However, the experimental results show that the rate of increase of the modulus of elasticity tends to decrease, which is expected as a result of the heterogeneity of the mixing caused by the increase of the filler content. As the filler content increases, the filler-filler bond increases as compared to the filler-matrix bond, and this tendency causes a difference from the actual predictive model.

The Nicolais \& Narkis model was used to predict the strength change of the composite with varying particle content.

$$
f_{\text {com }}=f_{m}\left(1-k V_{f}\right)
$$

$\mathrm{f}_{\text {com }}$ is tensile strength of composites, $\mathrm{fm}$ is tensile

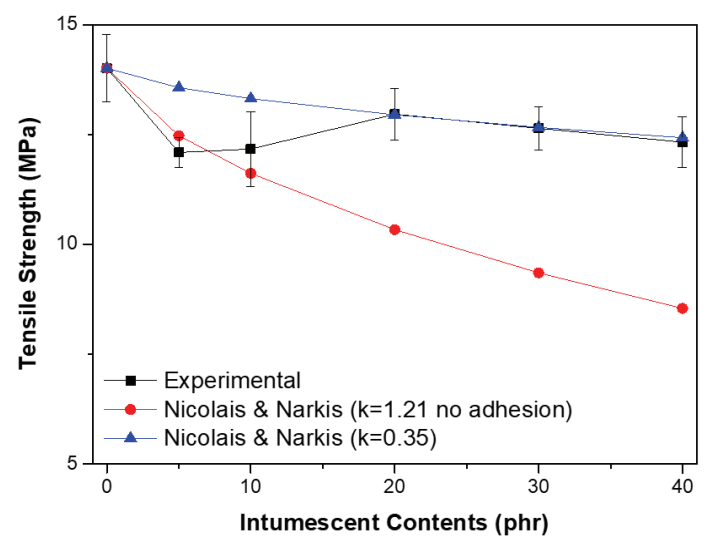

Fig. 2. Tensile strength of intumescent/EVA composites. strength of matrix and $k$ is the coefficient for the interaction between the filler and the matrix. The characteristic of the Nicolais \& Narkis model is that $\mathrm{k}$ can vary depending on the bond strength between materials. In general, $\mathrm{k}=1.21$ is modeled as the limit value (lower bound), which means that there is no mutual coupling force. Assuming that there is no bonding force between intumescent agent and EVA, the strength reduction is expected to be as shown in Fig. 2. However, the experimental results show a big difference from the above prediction models. This means that the matrix and filler are not in perfect separation. From the experimental results, it is predicted that $\mathrm{k}$ is about 0.35 , and the result is very similar to the actual result if the result is fitted by the factor. The smaller $\mathrm{k}$ is, the stronger the bond between the matrix and the filler. The results of $\mathrm{k}$ can not be expressed as absolute values, but it is generally known that $\mathrm{k}$ in composite materials using particles has a value of about 0.2 to 0.5 .

Based on the intumescent/EVA composite material evaluated above, we evaluated the strength change of the material reinforced with kenaf. The initial modulus of elasticity was constantly increased as the content of Kenaf increased from 19.9 MPa to $32.3 \mathrm{MPa}$

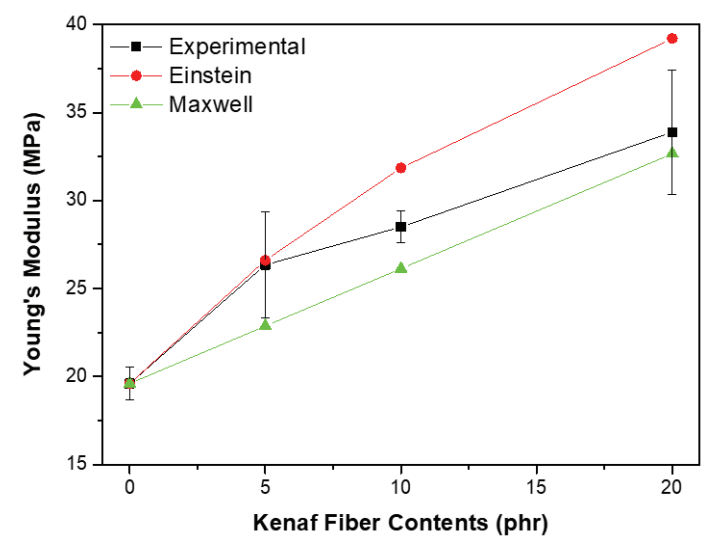

Fig. 3. Elastic modulus of intumescent/EVA/kenaf composites. 
(Fig. 3). It is evaluated as a result of reflecting the characteristics of fiber reinforced polymer (FRP). The modeling was carried out to assume that the matrix material is a composite material in which intumescent agent and EVA are mixed at a ratio of 10: 4 . In the modeling evaluation of the above particle based composite material, the Einstein model showed a lower tendency than the experimental results, but the composite material evaluation shows a lower tendency than the predicted results. This is because the effect of strengthening the fiber of the FRP is eliminated and the interaction between the particle and the fiber is neglected at the assuming stage. On the other hand, when Maxwell model which is a prediction model of the modulus of elasticity of the composite material using fiber is used, it can be confirmed that the difference from the experimental result is very small. In the case of the Maxwell model, the elastic modulus of the filler is reflected in the prediction model.

$$
E=\frac{E_{m} E_{f}}{\left(1-V_{f}\right) E_{f}+V_{f} E_{m}}
$$

In the strength evaluation, it tends to decrease as the content increases from the initial $12.4 \mathrm{MPa}$ to the final 11.1 MPa (Fig. 4). Generally, FRP that prepared

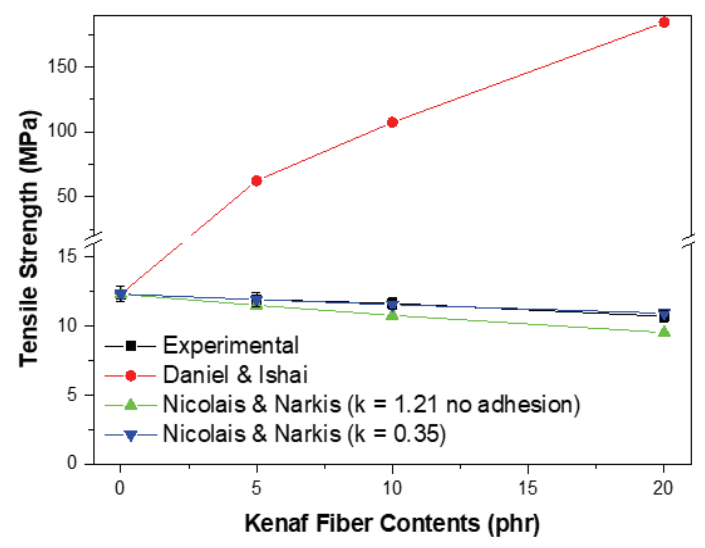

Fig. 4. Tensile strength of intumescent/EVA/kenaf composites. for strength reinforcement effect should increase in strength as fiber content increases. These results can be seen in the daniel $\&$ ishai model.

$$
f_{\text {com }}=f_{f i b} V_{f}+f_{m}\left(1-V_{f}\right)
$$

In the equation, $f_{\text {fib }}$ means the tensile strength of the fiber, which means that the strength of the composite can be expressed as the sum of the product of the volume ratio and the strength of the two materials. The tensile strength of the kenaf fiber used in the Daniel \& Ishai model was $930 \mathrm{MPa}$, which was shown in A, and the bulk fiber strength was used without pre-treatment. Because of the use of kenaf, which has a very high tensile strength compared to intumescent/EVA (12.4 $\mathrm{MPa}$ ) composite, the strength must increase linearly with very large slopes when using the previous model. However, since the strength is decreasing in this result, it can be said that the application of this model is not suitable. In order for this model to be used correctly, the coupling between the fiber and the matrix should be excellent, so that energy transfer between the fibers and the matrix should be easy. However, if we deduce the bond strength between two materials based on the results, it is considered that it is not sufficient for energy transfer.

The analysis of the system using the Nicolais \& Narkis model, which analyzes the system based on the low cohesion between the two materials, shows a very similar tendency. In the case of $\mathrm{K}=1.21$, it can be confirmed that the decrease is larger than that in the experiment. Based on the experimental results, $\mathrm{k}=0.35$ can be obtained. As with previous particle composites, it can be seen that the use of fiber has a negative effect on the strength change of the system. As a result, it can be confirmed that the bonding between the composite material and the kenaf is not sufficiently progressed. In general, the bonding strength between natural fibers and matrix in natural fiber-reinforced composite materials is a big problem in the process 
Evaluation of Mechanical Performance and Flame Retardant Characteristics of Biomass-based EVA Composites using Intumescent Flame Retardant Technology

of manufacturing composite materials. Since the mutual bonding force is weak, it is difficult to expect the effect of the fiber composite material. These problems are generally caused by different polarity between the fiber and the matrix and foreign matter on the surface of the natural fiber. In order to overcome the problem, the fiber surface modification and coupling agent should be used in process. In this study, since the fibers were directly used without such a process, the bonding force between the fibers and the matrix is very low. At the same time, the previously used particles induce an unspecified phenomenon at the fiber interface. These results

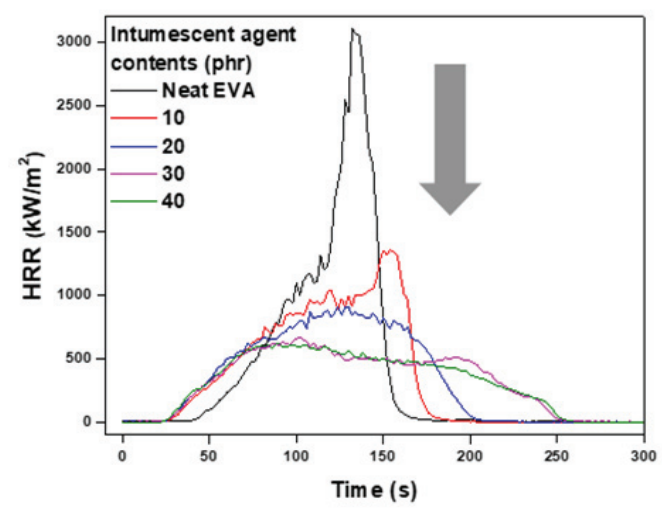

(a)

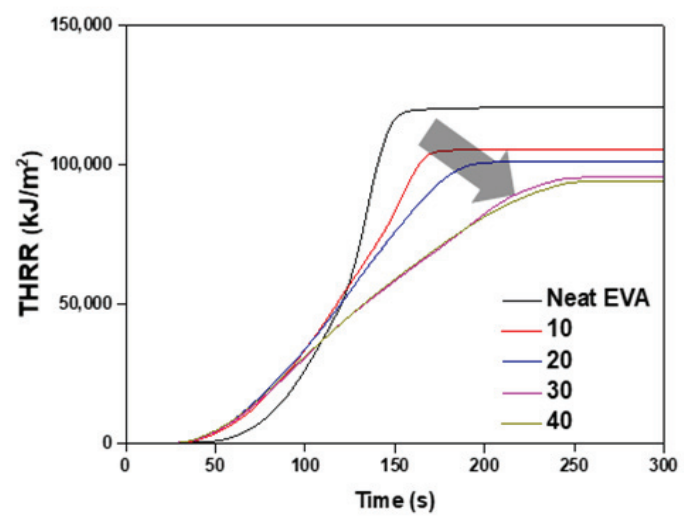

(c) are considered to have affected the strength reduction.

\subsection{Combustion Characteristics}

The combustion characteristics of particle composites using Intumescent agent were investigated. The experimental results are shown in Fig. 5. As the particle content increased, the combustion characteristics were improved. The maximum amount of combustion decreases up to $626 \mathrm{~kW} / \mathrm{m}^{2}$ as the content increases up to $40 \mathrm{phr}$ from a maximum of $3116 \mathrm{~kW} / \mathrm{m}^{2}$, showing a maximum reduction of about $80 \%$. Average heat

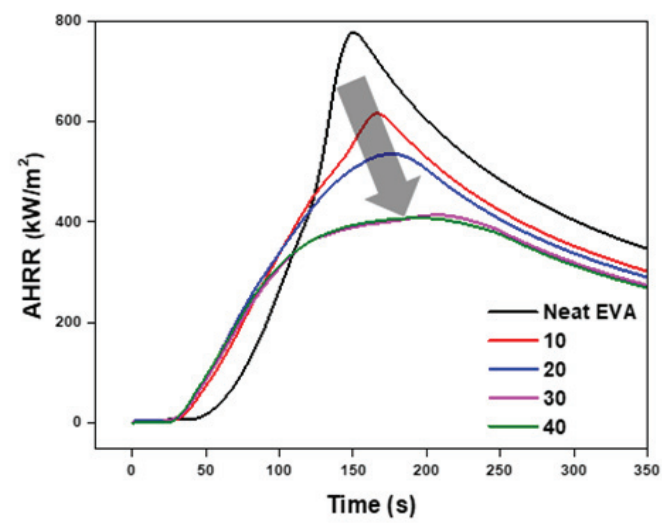

(b)

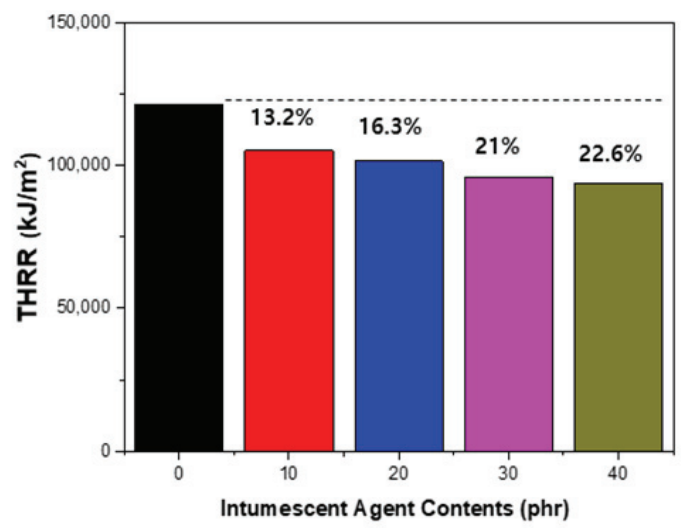

(d)

Fig. 5. Evaluation of Cone Calorimeter combustion performance of intumescent/EVA composites (a) Test result (b) AHRR (c) THRR depend on Time (d) THRR at final status. 


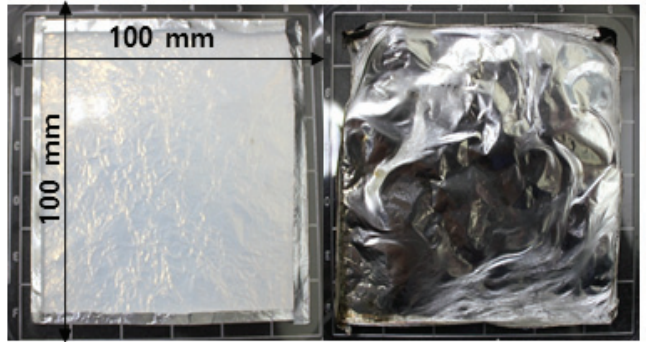

(a)

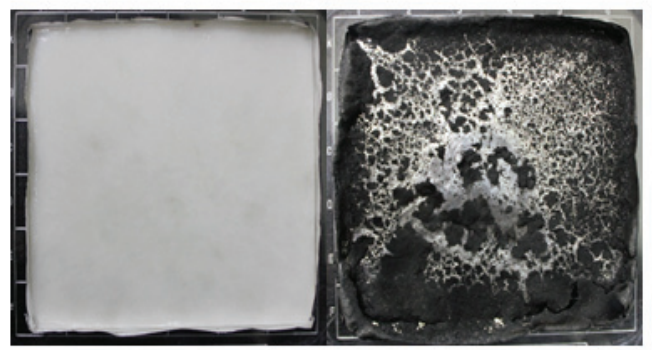

(c)

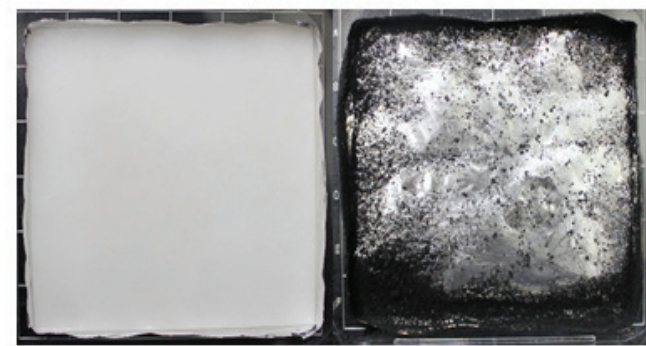

(b)

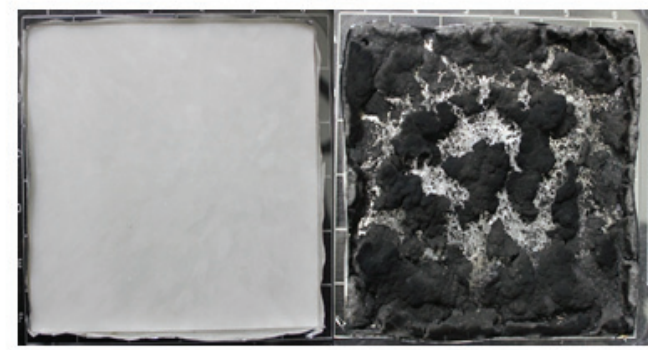

(d)

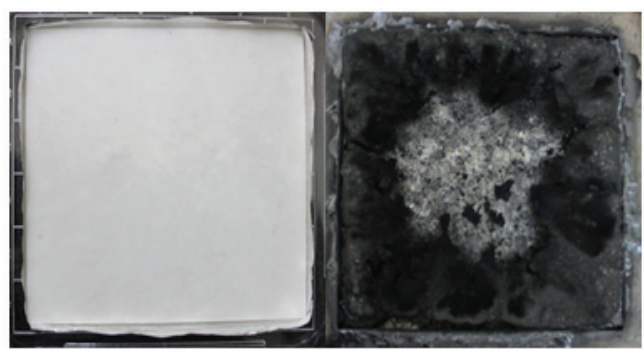

(e)

Fig. 6. Combustion residues of Intumescent/EVA composites after cone calorimeter (a) Neat EVA (b) Intumescent agent $10 \mathrm{phr}$ (c) $20 \mathrm{phr}$ (d) $30 \mathrm{phr}$ (e) $40 \mathrm{phr}$.

release rate (AHRR) which characterizes the combustion process of the entire material, also tends to decrease overall, while at the same time it can be seen that the maximum burn point is continuously shifted to the right. That is, it can be analyzed as a tendency that the combustion heat is not only reduced but also delayed when the combustion is grown. It can be confirmed that the calorific value of the entire material is also effectively reduced.

Fig. 6 shows a photograph of the combustion residue after the cone calorimeter experiment. The left side of each figure shows the specimen of the sheet shape before the experiment, and the right side is the ash photograph after combustion. In the case of Fig. 6(a) in which no intumescent was introduced at all, it can be confirmed that complete combustion has proceeded and no remnants remain. As the content of intumescent agent increases, the content of ash increases. This is a reflection of the formation of carbonization, which is characteristic of the intumescent system. When the content of intumescent increases up to $40 \mathrm{phr}$, it forms a carbonized layer. This carbonized layer plays a role 
Evaluation of Mechanical Performance and Flame Retardant Characteristics of Biomass-based EVA Composites using Intumescent Flame Retardant Technology

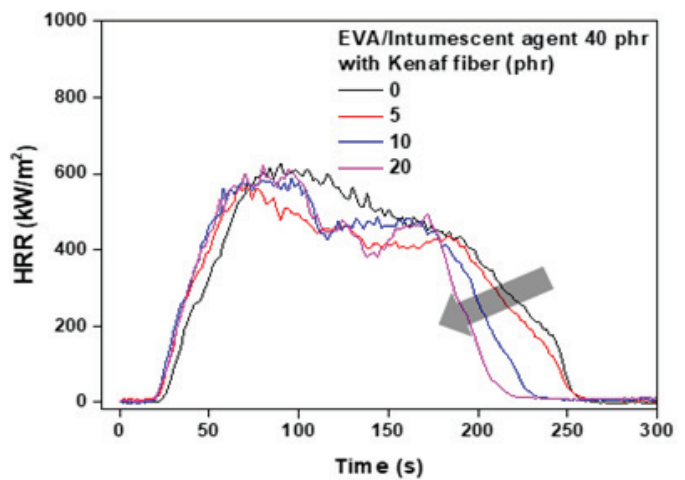

(a)

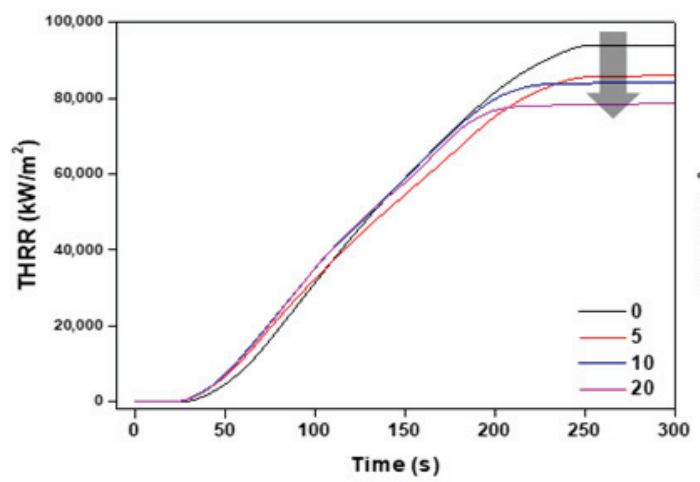

(c)

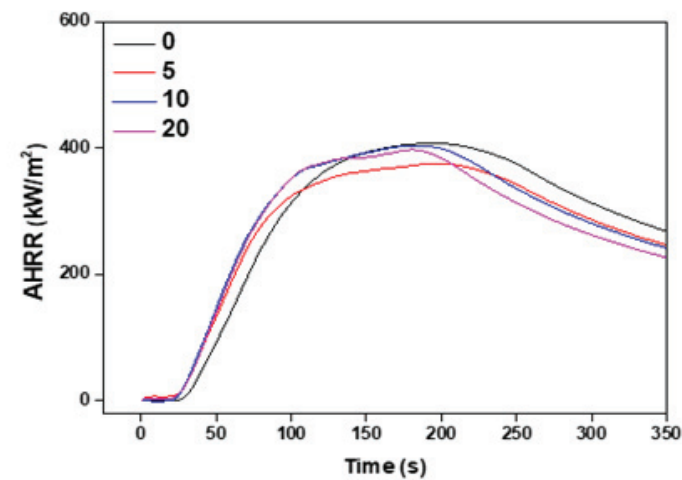

(b)

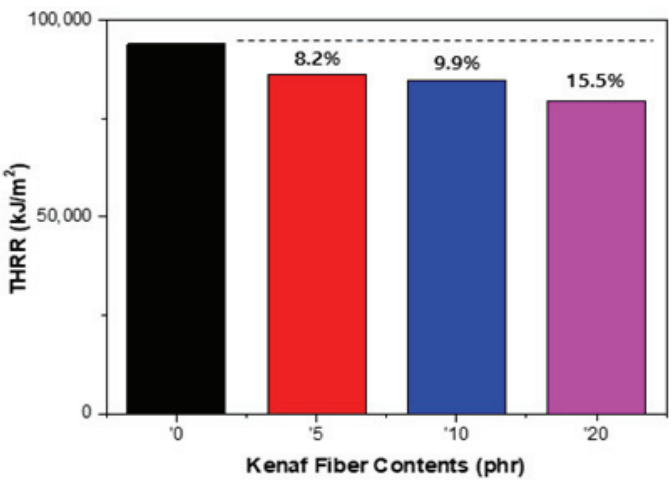

(d)

Fig. 7. Evaluation of cone calorimeter combustion performance of intumescent/EVA/kenaf composites (a) Test result (b) AHRR (c) THRR depend on Time (d) THRR at final status.

in inducing flame retardation in the combustion process. In order for the carbide to be formed into a tight layer, a material capable of forming a layer is required. Lee and Park have used plate-like materials such as nano-clay to form a carbonized layer.

Lignocellulogic materials, such as Kenaf, are known to be vulnerable to combustion characteristics, and these properties are expected to apply equally to composite materials. Generally, since the natural thermal degradation temperature of the lignocellulosic material is known to be around $400{ }^{\circ} \mathrm{C}$, it has a disadvantage vulnerable to initial ignition. Experimental results were evaluated differently from these trends (Fig. 7). First, the maximum calorific value tends to decrease by $9.3 \%$ when $5 \mathrm{phr}$ of kenaf is used, and it does not exceed the existing maximum calorific value even if it increases up to $20 \mathrm{phr}$. On the other hand, there is no phenomenon in which the initiation is pulled, but the combustion end is advanced 50 seconds. In the AHRR evaluation, the overall heating characteristics are improved compared to before using kenaf. In the total calorific value evaluation, as the use amount increased, it decreased continuously, and a total calorific value reduction of $15.5 \%$ was measured when using $20 \mathrm{phr}$ of kenaf. Compared to petroleum based EVA materials, kenaf exhibits strong combustion characteristics. Resins such as lignin and foreign matter on the surface show strong characteristics in combustion. Also, since the cellulose 


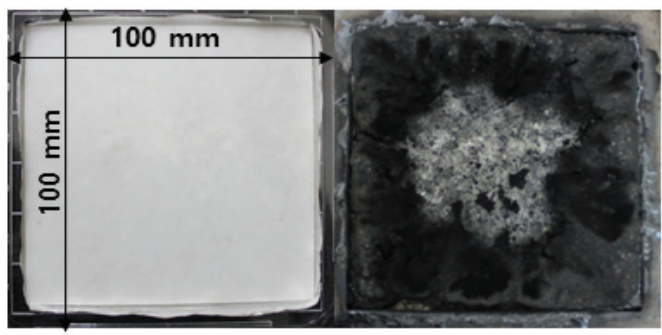

(a)

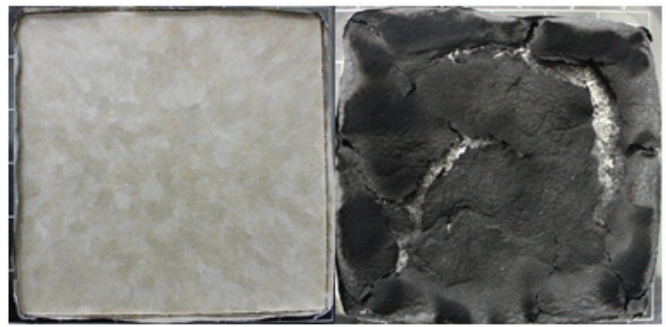

(c)

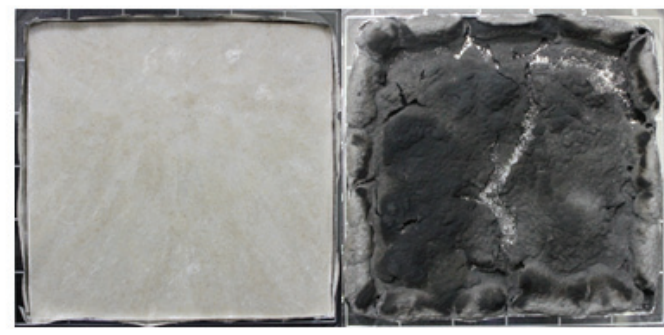

(b)

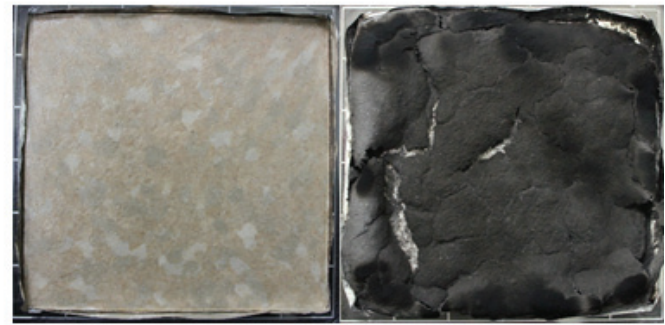

(d)

Fig. 8. Combustion residues of Intumescent/EVA/kenaf composites after Cone Calorimeter (a) Intumescent $40 \mathrm{phr}$ (b) Intumescent with kenaf $5 \mathrm{phr}$ (c) $10 \mathrm{phr}$ (d) $20 \mathrm{phr}$.

structure forms a strong packing, it has strong resistance in combustion.

Fig. 8 is a photograph of the residue after combustion of the composite material using kenaf. By using kenaf, we can identify layers that were not visible when the intumescent agent alone was used. These layers are evaluated as the result of the carbonized layer formation of the intumescent agent with kenaf carbonized fibers forming a firm layer. As mentioned above, there are agents used for the formation of carbonized layer, in which case carbonized fibers of kenaf play such a role. Generally, the lignocellulosic based material exhibits the internal combustion retardation effect according to the carbonized layer after the primary carbonization. As the amount of kenaf fiber is increased, a stronger layer is formed. The formation of such a carbonized layer is a major factor that can exhibit the combustion retarding effect in the combustion process. kenaf etc. are highly likely to be used as natural fiber reinforcements.

Unlike cone calorimeter experiments, UL 94 is an experiment to verify direct surface carbonization and combustion for fire exposure. Table 3 shows the UL94 test results for each composite system. When the intumescent agent is used alone in the EVA resin, the flame retardancy is enhanced as the content increases. When the initial content is small (10 phr), the resin tends to be completely burned as can be seen in the table 3. When the amount of the intumescent agent is increased, the length of the complete combustion layer on the composites surface is reduced. When the intumescent agent of $40 \mathrm{phr}$ is used, all $\mathrm{T} 1$ reaches 0 seconds and a complete V2 grade material can be obtained.

T1 represents the burning time of the specimen after the flushing of the flame. It means continuous burning characteristics after departing from the fire source. The higher (=shorter times) result means that the initial 
Evaluation of Mechanical Performance and Flame Retardant Characteristics of Biomass-based EVA Composites using Intumescent Flame Retardant Technology

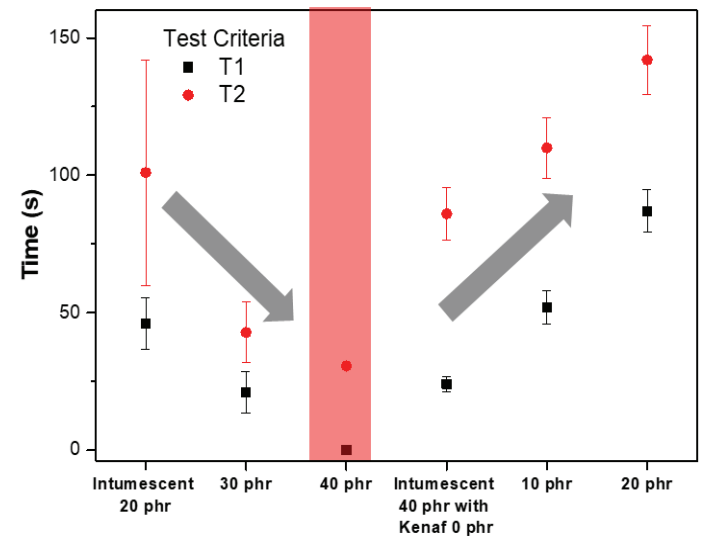

Fig. 9. T1/T2 change according to composition ratio of composites.

combustion characteristics are strengthened. After that, the re-flushing proceeds to confirm the combustion characteristics, and this characteristic is evaluated as T2. The intumescent system, which has already formed a carbonized layer, shows excellent characteristics in secondary combustion.

In the UL 94 evaluation, the increase in the content of Kenaf tends to enhance the carbonization characteristics.
As listed in Table 4, it can be seen that the carbonation length continuously increases as the utilization of kenaf increases. In addition, both $\mathrm{T} 1 / \mathrm{T} 2$ tend to increase steadily, and when using more than $20 \mathrm{phr}$, V2 grade is not reached. The overall pattern of change in $\mathrm{T} 1$ and T2 is shown in Fig. 9. In the case of using kenaf, the cone calorimeter experiment showed a tendency to decrease the calorific value, whereas the UL94 experiment showed the opposite result that the carbonization accelerated. Because the cone calorimeter test evaluates the combustion characteristics in the complete combustion condition, the constituents of the material and the elements in the combustion process are reflected in the experiment. On the other hand, the UL94 test is a test for initial combustion growth of the flame that is directly reflected on the surface carbonization. According to the application of kenaf, the flame retardant grade according to UL 94 tends to be lowered, but the V2 grade can be maintained up to 10 phr. From this characteristic, it is confirmed again that kenaf fiber is applicable to flame retardant composite materials.

Table 3. UL 94 test results of Intumescent/EVA composites

\begin{tabular}{|c|c|c|c|c|c|c|c|c|c|c|c|c|}
\hline \multirow{2}{*}{$\begin{array}{l}\text { Sample } \\
\text { Repeat }\end{array}$} & \multicolumn{3}{|c|}{$\begin{array}{c}\text { Intumescent } \\
10(\mathrm{phr})\end{array}$} & \multicolumn{3}{|c|}{20} & \multicolumn{3}{|c|}{30} & \multicolumn{3}{|c|}{40} \\
\hline & 1 & 2 & 3 & 1 & 2 & 3 & 1 & 2 & 3 & 1 & 2 & 3 \\
\hline $\mathrm{T} 1$ (sec) & - & - & - & 12 & 26 & 8 & 0 & 15 & 6 & 0 & 0 & 0 \\
\hline $\mathrm{T} 2(\mathrm{sec})$ & - & - & - & 10 & 81 & 10 & 12.8 & 4 & 26 & 10 & 10.8 & 9.8 \\
\hline T3 (sec) & - & - & - & 0 & 0 & 0 & 0 & 0 & 0 & 0 & 0 & 0 \\
\hline Un to Clamp & Yes & Yes & Yes & No & No & No & No & No & No & No & No & No \\
\hline $\begin{array}{c}\text { Cotton indicator } \\
\text { ignited }\end{array}$ & Yes & Yes & Yes & Yes & Yes & Yes & Yes & Yes & Yes & Yes & Yes & Yes \\
\hline \multicolumn{13}{|l|}{ Test Specimen } \\
\hline Grading & & None & & & $\mathrm{V} 2$ & & & $\mathrm{~V} 2$ & & & $\mathrm{~V} 2$ & \\
\hline
\end{tabular}


Table 4. UL 94 test results of Intumescent/EVA/kenaf composites

\begin{tabular}{|c|c|c|c|c|c|c|c|c|c|c|c|c|}
\hline Sample & \multicolumn{3}{|c|}{$\begin{array}{l}\text { Kenaf } \\
0 \mathrm{phr}\end{array}$} & \multicolumn{3}{|c|}{5} & \multicolumn{3}{|c|}{10} & \multicolumn{3}{|c|}{20} \\
\hline Repeat & 1 & 2 & 3 & 1 & 2 & 3 & 1 & 2 & 3 & 1 & 2 & 3 \\
\hline $\mathrm{T} 1 \quad(\mathrm{sec})$ & 0 & 0 & 0 & 5 & 9 & 10 & 11 & 18 & 23 & 38 & 24 & 25 \\
\hline $\mathrm{T} 2(\mathrm{sec})$ & 10 & 10.8 & 9.8 & 19 & 29 & 38 & 38 & 47 & 25 & 47 & 60 & 35 \\
\hline $\mathrm{T} 3$ (sec) & 0 & 0 & 0 & 0 & 0 & 0 & 0 & 0 & 0 & 0 & 0 & 0 \\
\hline Un to Clamp & No & No & No & No & No & No & No & No & No & No & No & No \\
\hline $\begin{array}{c}\text { Cotton indicator } \\
\text { ignited }\end{array}$ & Yes & Yes & Yes & Yes & Yes & Yes & Yes & Yes & Yes & Yes & Yes & Yes \\
\hline Test Specimen & & & & & & & & & & & & \\
\hline Grading & & V2 & & & V2 & & & $\mathrm{V} 2$ & & & None & \\
\hline
\end{tabular}

\section{CONCLUSION}

Although it was possible to secure a high elastic modulus in the process of improving the strength of the composite material on the existing particles through natural fibers, it was not effective in directly enhancing the physical properties such as tensile strength. Since EVA-based flame retardant materials are used in the form of sheet, it is essential to maintain the shape after film molding. Therefore, strengthening the modulus of elasticity helps to maintain such a shape. On the other hand, it is a factor to be overcome because the film may be stretched or broken due to the decreasing tensile strength.

The use of lignocellulosic fibers such as kenaf was anticipated to be an impediment to flame retardant properties. However, the flame retardancy was not significantly degraded at the initial $10 \mathrm{phr}$ level. However, the progress of surface carbonization due to the combustion transition on the fiber surface is evaluated as a factor to overcome in the future. In order to improve the problems pointed out in this study, the surface modification study of kenaf fiber is considered to be indispensable and it is possible to develop a natural fiber based flame retardant composite material with improved strength and flame retardant properties.

\section{ACKNOWLEDGMENT}

This research was supported by the Fire Fighting Safety \& 119 Rescue Technology Research and Development Program funded by the Ministry of Public Safety and Security (NEMA-Next generation-201458-2) and grant (17CTAP-C133412-01) from Infrastructure and Transportation Technology Promotion Research Program funded by Ministry of Land, Infrastructure and Transport of Korean government.

\section{REFERENCES}

Choi, C., Yuk, C.R., Yoo, J.C., Park, J.Y., Lee, C.G., Kang, S.G. 2015. Physical and mechanical properties of cross laminated timber using plywood as core layer. Journal of the Korean Wood Science and Technology 43(1): 86-95.

Daniel, I.M., Ishai, O., Daniel, I.M., Daniel, I. 1994. 
Evaluation of Mechanical Performance and Flame Retardant Characteristics of Biomass-based EVA Composites using Intumescent Flame Retardant Technology

Engineering mechanics of composite materials Vol.

3. New York: Oxford University Press. pp. 256-256.

Einstein, A. 1905. Über die von der molekularkinetischen

Theorie der Wärme geforderte Bewegung von in ruhenden Flüssigkeiten suspendierten Teilchen. Annalen der Physik 322(8): 549-560.

Govindjee, S., Simo, J.C. 1992. Mullins' effect and the strain amplitude dependence of the storage modulus. International Journal of Solids and Structures 29(14-15): 1737-1751.

Grexa, O., Horváthová, E., Lehocký, P. 1999. Flame retardant treated plywood. Polymer Degradation and Stability 64(3): 529-533.

Gu, J.W., Zhang, G.C., Dong, S.L., Zhang, Q.Y., Kong, J. 2007. Study on preparation and fire-retardant mechanism analysis of intumescent flame-retardant coatings. Surface and Coatings Technology 201 (18): 7835-7841.

Guth, E. 1945. Theory of filler reinforcement. Journal of Applied Physics 16(1): 20-25.

Harper, C.A. 2004. Handbook of building materials for fire protectionNew. York: McGraw-Hill. pp. 7-1.

Horrocks, A.R., Price, D., Price, D. (Eds.). 2001. Fire retardant materials. Woodhead Publishing.

Hwang, E.-C., Kwon, Y.-J. 2017. A study on the fire risk of urban type housing constructed by pilotis structures: In the case of Uijeongbu fire. Proceeding of Annual Meeting of Korea Institute of Building Construction 17(1): 50-51.

Hwang, T.S., Lee, B.J., Yang, Y.K., Choi, J.H., Kim, H.J. 2005. The R\&D trends of polymer flame retardants. Prospect Ind Chem., 8(6): 36-40.

Jang, B.N., Choi, J. 2009. Research trend of flame retardant and flame retardant resin. Polymer Science and Technology 20(1): 8-15.

Kim, J.I., Park, J.Y., Kong, Y.T., Lee, B.H., Kim, H.J., Roh, J.K. 200). Performance on flame-retardant polyurethane coatings for wood and wood-based materials. Journal of the Korean Wood Science and Technology 30(2): 172-179.
Kinloch, A.J., Maxwell, D.L., Young, R.J. 1985. The fracture of hybrid-particulate composites. Journal of Materials Science 20(11): 4169-4184.

Lavengood, R.E., Nicolais, L., Narkis, M. 1973. A deformational mechanism in particulate-filled glassy polymers. Journal of Applied Polymer Science 17(4): 1173-1185.

Levchik, S.V., Weil, E.D. 2006. A review of recent progress in phosphorus-based flame retardants. Journal of Fire Sciences 24(5): 345-364.

Li, B., Xu, M. 2006. Effect of a novel charring-foaming agent on flame retardancy and thermal degradation of intumescent flame retardant polypropylene. Polymer Degradation and Stability 91(6): 1380-1386.

Lu, S.Y., Hamerton, I. 2002. Recent developments in the chemistry of halogen-free flame retardant polymers. Progress in Polymer Science 27(8): 16611712.

Nicolais, L., Narkis, M. 1971. Stress-strain behavior of styrene-acrylonitrile/glass bead composites in the glassy region. Polymer Engineering \& Science 11(3): 194-199.

Son, D.W., Kang, M.R., Lee, D.H., Park, S.B. 2013. Decay resistance and anti-mold efficacy of wood treated with fire retardants. Journal of the Korean Wood Science and Technology 41(6): 559-565.

Son, D.W., Eom, C.D., Park, J.C., Park, J.S. 2014. Performance of structural glulam manufactured with fire retardants treated lumbers. Journal of the Korean Wood Science and Technology 42(4): 477-482.

Tang, Y., Hu, Y., Wang, S., Gui, Z., Chen, Z., Fan, W. 2003. Intumescent flame retardant-montmorillonite synergism in polypropylene-layered silicate nanocomposites. Polymer international 52(8): 1396-1400.

Wu, K., Hu, Y., Song, L., Lu, H., Wang, Z. 2009. Flame retardancy and thermal degradation of intumescent flame retardant starch-based biodegradable composites. Industrial \& Engineering Chemistry Research 48(6): 3150-3157. 